\title{
CHEMICAL STABILITY OF ENALAPRIL MALEATE DRUG SUBSTANCE AND TABLETS BY A STABILITY- INDICATING LIQUID CHROMATOGRAPHIC METHOD
}

Marta de Diego*, Gloria Godoy, Sigrid Mennickent and Ricardo Godoy

Pharmacy Department, Pharmacy School, University of Concepción, PO Box 237, Concepción, Chile

Recebido em 22/6/10; aceito em 1/10/10; publicado na web em 26/1/11

\begin{abstract}
The chemical stability of enalapril drug substance and tablets was studied by a stability-indicating liquid chromatographic method. Stress testing was performed on drug substance under various conditions. Accelerated stability testing was carried out for different formulations of enalapril tablets. Chromatographic separation was achieved on a RP-18 column, using a mobile phase of methanol phosphate buffer at $1.0 \mathrm{~mL} \mathrm{~min}^{-1}$ and UV detection. Degradation of the drug substance was greater under hydrolytic conditions. After 180 days of accelerated stability testing most enalapril tablets showed more than $10 \%$ of degradation. Enalapril drug substance and tablets showed instability under stress and accelerated testing respectively, with possible implications on the therapeutic activity.
\end{abstract}

Keywords: enalapril; stability; liquid chromatography.

\section{INTRODUCTION}

The stability of a pharmaceutical preparation is in relation with its potency, therefore, with its therapeutic properties. Chemical degradation of the active constituent often results in a loss of potency, or in a few instances the degradation products may be toxic, so that clinical use of a pharmaceutical preparation can not be recommendable if the degradation is relatively high. ${ }^{1}$

Different factors can affect the stability of drug substances and dosage form; these include intrinsic factors such as the molecular structure of the drug itself and environmental factors, such as temperature, light, humidity and oxygen. ${ }^{1-3}$ For many pharmaceutical preparations, $90 \%$ of labelled potency is generally recognized as the minimum acceptable potency level. ${ }^{4}$

Enalapril (Figure 1) is an angiotensin-converting enzyme (ACE) inhibitor used in the treatment of hypertension. It is a prodrug which has an ester group in their molecular structure therefore it is susceptible to degradation, it is rapidly absorbed after oral administration as its maleate salt and has little pharmacologic activity until hydrolyzed in the liver to enalaprilat. ${ }^{5}$<smiles>CCOC(=O)[C@H](C)N[C@H](C)C(=O)N1CCCC1C(=O)O</smiles>

Figure 1. Molecular structure of enalapril. The structure enclosed within box is replaced with a hydrogen atom to form the active molecule in vivo (enalaprilat)

It is reported that enalapril degrades to two major degradation products; enalaprilat and diketopiperazine derivative (DKP). ${ }^{6-11}$

Most of the reported methods for quantitative determination of enalapril in pharmaceutical samples, ${ }^{6-14}$ including official method, ${ }^{2}$ are by liquid chromatography with UV detection using a high column temperature. Other techniques include liquid chromatography-mass spectrometry for analysis in biological samples. ${ }^{15,16}$

*e-mail: mdediego@udec.cl
The objectives of this study were to develop and validate a simple stability-indicating LC method for enalapril, to determine the chemical stability of enalapril maleate drug substance under various ICH (International Conference on Harmonization) stress testing, and to evaluate the stability of different formulations of enalapril tablets under accelerated storage conditions according to the ICH stability testing guidance. ${ }^{17}$

\section{EXPERIMENTAL}

\section{Reagents and chemicals}

Standard of enalapril maleate and salicylic acid ( $>99.0 \%$ purity) were obtained from Sigma (St. Louis, MO, USA). Standard of enalaprilat was obtained from USP (Rockville, MD, USA). Methanol LC grade, $\mathrm{KH}_{2} \mathrm{PO}_{4}$, sodium hydroxide, hydrochloric acid and hydrogen peroxide p.a. grade were from Merck (Darmstadt, Germany). Enalapril maleate drug substance was obtained from Diprolab (Santiago, Chile). Seven commercial products of enalapril maleate tablets $10 \mathrm{mg}$ were studied; three registered trade (RA, RB, RC) and three generic products (GA, GB, GC) were purchased from a Chilean pharmacy, and reference product $(\mathrm{S})$ was purchased from the Argentine market. RA and GA were from the same manufacturer.

\section{Instrumentation}

For stability studies a climate chamber KBF-115 Binder (Tuttlingen, Germany) was used. Chromatography was performed by using a Perkin Elmer Series 200 liquid chromatograph (Norwalk, CT, USA) equipped with a manual injector, a 7125 Rheodyne injection valve (Cotati, CA, USA), and a 20- $\mu$ L loop. An Applied Biosystems Model 785A programmable absorbance detector (Foster, CA, USA), and a Perkin Elmer Nelson Model 1022 data processor (Norwalk, CT, USA).

\section{Chromatographic conditions}

All analyses were performed at room temperature $\left(23 \pm 2{ }^{\circ} \mathrm{C}\right)$ under isocratic conditions. The separation was carried out using a 
Purospher ${ }^{\circledR}$ RP-18 column (150 mm x 4.6 mm, $5 \mu \mathrm{m}$; Merck, Darmstadt, Germany). The mobile phase consisted of methanol - phosphate buffer $(\mathrm{pH} 2.2 ; 0.01 \mathrm{M})(55: 45, \mathrm{v} / \mathrm{v})$. The UV detection was made at $215 \mathrm{~nm}$ and the flow rate was $1.0 \mathrm{~mL} / \mathrm{min}$. Salicylic acid $(60 \mu \mathrm{g} / \mathrm{mL})$ was used as the internal standard.

\section{Preparation of standard solutions}

A stock solution of enalapril maleate and a stock solution of salicylic acid were independently prepared at about 2.0 and $3.0 \mathrm{mg} / \mathrm{mL}$ respectively in methanol. Standard solutions were prepared from the stock solution after adequate dilution with water. A stock solution of enalaprilat was prepared in methanol at $1 \mathrm{mg} / \mathrm{mL}$. Diketopiperazine degradation product was produced from standard of enalapril maleate according to the USP method. ${ }^{2}$

\section{Sample preparation}

Ten tablets of enalapril maleate $10 \mathrm{mg}$ were weighed and powered. A portion equivalent to $10 \mathrm{mg}$ of enalapril maleate was accurately weighed and transferred to a $50 \mathrm{~mL}$ volumetric flask. A portion of 1 $\mathrm{mL}$ of internal standard $(3 \mathrm{mg} / \mathrm{mL}$ ) was added (final concentration of $60 \mu \mathrm{g} / \mathrm{mL}$ ), and diluted with water to volume (final concentration of enalapril; $200.0 \mu \mathrm{g} / \mathrm{mL}$ ). Then they were vortexed for $15 \mathrm{~s}$, filtered and centrifuged for $5 \mathrm{~min}$, and the supernatant was chromatographed.

\section{Stability-indicating capability of the LC assay}

It was established by chromatographic analysis of all stressed samples (as explained in section stress testing) and standard solutions of the main degradation products of enalapril (enalaprilat and diketopiperazine). The composition, $\mathrm{pH}$ and the flow rate of the mobile phase were changed to optimize separation between enalapril, internal standard and the degradation products.

\section{Method validation}

The method was validated according to the ICH guidelines for validation of analytical procedures. ${ }^{18}$ The parameters validated were linearity, precision, accuracy, selectivity, detection and quantitation limits.

\section{Stability studies}

Stress and accelerated stability testing were carried out according to the ICH stability testing guidance. ${ }^{17}$

\section{Stress testing}

Enalapril maleate was stressed under various conditions; until to facilitate approximate $5-20 \%$ degradation. ${ }^{19}$ For each condition, a blank solution was prepared and was subjected to stress in the same manner as the drug, also it was prepared a control solution of enalapril maleate, which was stored without the stress condition. Prior to analysis, samples were diluted to $200 \mu \mathrm{g} / \mathrm{mL}$.

\section{Hydrolysis}

It was established by forced decomposition of enalapril maleate $2 \mathrm{mg} / \mathrm{mL}$ in $0.1 \mathrm{~N}$ hydrochloric acid, water and $0.1 \mathrm{~N}$ sodium hydroxide. Samples of $5 \mathrm{~mL}$ for each time point were kept on a hot plate at $60{ }^{\circ} \mathrm{C}$ for basic hydrolysis and at $80{ }^{\circ} \mathrm{C}$ for acid and neutral hydrolysis, (total time for basic hydrolysis $30 \mathrm{~min}$. Total time for acid and neutral hydrolysis $24 \mathrm{~h}$ ), after which they have been cooled to room temperature, then they were transferred to a $50 \mathrm{~mL}$ volumetric flask, a $1 \mathrm{~mL}$ of internal standard $(3.0 \mathrm{mg} / \mathrm{mL})$ was added, then they were diluted to volume and analyzed by the LC method. In order to determine de degradation kinetics, graphs of the $\log \%$ residual versus time were obtained.

Oxidation

Oxidation of enalapril maleate was carried out in $3 \% \mathrm{H}_{2} \mathrm{O}_{2}$ at a concentration of $2 \mathrm{mg} / \mathrm{mL}$, at room temperature $\left(25 \pm 2{ }^{\circ} \mathrm{C}\right)$ for 8 days and $80^{\circ} \mathrm{C}$ for $6 \mathrm{~h}$, in the dark.

\section{Temperature}

Solid enalapril maleate was exposed to dry heat at $70^{\circ} \mathrm{C}$ in an oven and under controlled temperature of $40 \pm 2{ }^{\circ} \mathrm{C}$ and relative humidity of $75 \pm 5 \%$ in a climate chamber, for 27 days.

\section{Photostability}

An aqueous solution of enalapril maleate $2 \mathrm{mg} / \mathrm{mL}$ and solid drug in $1 \mathrm{~mm}$ layer in a petri-plate, were exposed to UV and VIS radiation for 7 days. Dark controls were run simultaneously.

\section{Accelerated stability testing}

Enalapril maleate tablets $10 \mathrm{mg}$ in their original packaging were stored under controlled temperature of $40 \pm 2^{\circ} \mathrm{C}$ and relative humidity of $75 \pm 5 \%$ in a climate chamber. Samples were taken at $0,30,90$ and 180 days and analyzed by LC to determine the enalapril amount. Each sample was analyzed in duplicate.

\section{RESULTS AND DISCUSSION}

\section{Stability-indicating LC method development and optimization}

The main target of the stability-indicating chromatographic method is to get the separation between enalapril and their degradation products. Reported LC methods for enalapril, used gradient and/ or a high column temperature, which requires more sophisticated instrumentation and/or long stabilization times. ${ }^{2,6-11,13,14}$ These methods mainly used acetonitrile and phosphate buffers of various $\mathrm{pH}$ in the mobile phase, therefore, different proportions of acetonitrile and change in $\mathrm{pH}$ were tested (50:50, 40:60, 30:70 v/v; $\mathrm{pH} 2.2, \mathrm{pH}$ 2.4, $\mathrm{pH} 2.6$ ), but under these conditions peak shapes were not good. Then methanol was tested instead of acetonitrile, obtaining good peak shapes. Interference with methanol absorption at $215 \mathrm{~nm}$ was not observed. After that, different proportions of methanol using phosphate buffers of various $\mathrm{pH}$ and different flow rate, at room temperature of the column, were evaluated before the final chromatographic conditions were selected. The mobile phase that best resolved enalapril maleate, degradation products of enalapril and salicylic acid, with sharp peaks was methanol - phosphate buffer $(\mathrm{pH} 2.2 ; 0.01 \mathrm{M})(55: 45$, $\mathrm{v} / \mathrm{v}$ ) at $1.0 \mathrm{~mL} / \mathrm{min}$. Figure 2 shows a chromatogram of stressed sample and internal standard, witch prove the stability-indicating capability of the assay.

\section{Method validation}

\section{Linearity}

The calibration curve of enalapril maleate was linear over the concentration range of 50.0 to $300.0 \mu \mathrm{g} / \mathrm{mL}$ (6 different concentrations were used and each solution was injected 5 times). The equation of the standard curve based on the ratio of the peak heights of enalapril maleate / internal standard to the enalapril maleate concentration was $y=0.0048 \pm 0.0001 x+0.0088 \pm 0.0048 ; r^{2}=0.9989 \pm 0.0003$.

Precision

The intra-day precision was determined by analysis of 3 different 


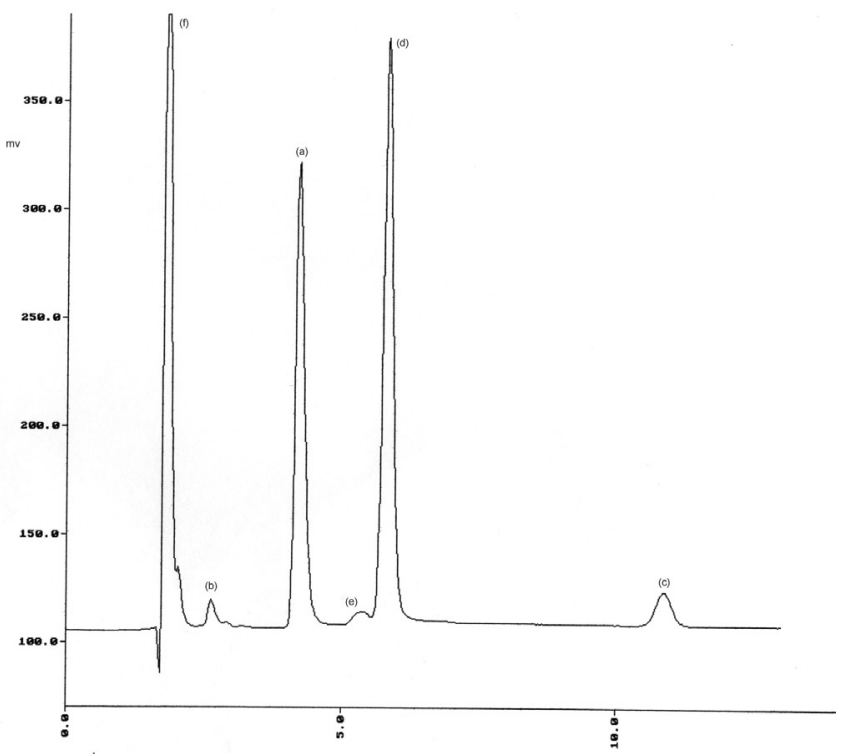

Figure 2. Representative chromatogram of stressed sample: enalapril (a), enalaprilat (b), diketopiperazine $(c)$, salicylic acid $(d)$, acidic degradation product (e) and maleic acid (f). $1 \mathrm{mV}: 0.001 \mathrm{AU}$

preparations in concentrations of $150.0,200.0$ and $250.0 \mu \mathrm{g} / \mathrm{mL}$ on the same day. The inter-day precision was studied by comparing the assays on 3 different days. The results are shown in Table 1. The obtained values show a suitable precision for the analytical method.

Table 1. Precision determined during method validation

\begin{tabular}{|c|c|c|}
\hline \multirow{2}{*}{$\begin{array}{l}\text { Concentration } \\
\qquad(\mu \mathrm{g} / \mathrm{mL})\end{array}$} & \multicolumn{2}{|c|}{ Relative standard deviation $(\%)$} \\
\hline & intra-day $^{\text {a) }}$ & inter-day $^{b}$ \\
\hline 150.00 & 0.68 & 1.62 \\
\hline 200.00 & 1.59 & 1.19 \\
\hline 250.00 & 0.96 & 1.30 \\
\hline
\end{tabular}

a) Analyzed on the same day $(n=3)$. b) Analyzed on 3 different days $(n=9)$.

\section{Accuracy}

To evaluate the accuracy of the method, recovery test were performed by adding know amounts of standard of enalapril maleate in the level 75,100 and $125 \%$ of the enalapril maleate levels in the tablets (3 replicates of each level) to common tablet excipients (lactose, starch and magnesium stearate). The accuracy of the assay was determined by comparing the found amount with the added amount. The results obtained are shown in Table 2. The obtained values confirm the accuracy of the proposed method.

Table 2. Recovery percentage of enalapril determined during method validation

\begin{tabular}{cccc}
\hline $\begin{array}{c}\text { Sample } \\
\text { level } \\
(\%)\end{array}$ & $\begin{array}{c}\text { Added } \\
\text { amount } \\
(\mathrm{mg})\end{array}$ & $\begin{array}{c}\text { Found } \\
\text { amount } \\
(\mathrm{mg})^{\mathrm{a})}\end{array}$ & $\begin{array}{c}\text { Recovery } \\
(\%)^{\mathrm{b})}\end{array}$ \\
\hline 75 & 7.50 & $7.63 \pm 0.05$ & 101.75 \\
100 & 10.00 & $9.90 \pm 0.16$ & 99.02 \\
125 & 12.50 & $12.70 \pm 0.12$ & 101.63 \\
\hline
\end{tabular}

a) Mean $\pm \operatorname{SD}(\mathrm{n}=3)$. b) (Found amount/Added amount) $x 100$.

\section{Selectivity}

The method is selective towards enalapril, degradation products, internal standard, and maleic acid (from maleate salt) as shown in Figure 2 . The selectivity was also evaluated by observing any interfer- ence from excipients used in the tablets; therefore a sample of each commercial product was analyzed without degradation, showing no peaks that interfered with enalapril, degradation products or internal standard. These results proved the selectivity of the proposed method.

\section{Detection and quantitation limits}

The DL and QL were calculated by using the equations: DL = $3.3 \times \sigma / \mathrm{S} ; \mathrm{QL}=10 \times \sigma / \mathrm{S}$, where $\sigma$ is the standard deviation of the response and $\mathrm{S}$ is the slope of the calibration curve. DL was 0.18 $\mu \mathrm{g} / \mathrm{mL}$ and $\mathrm{QL}$ was $0.56 \mu \mathrm{g} / \mathrm{mL}$. These values are adequate for the enalapril determination in pharmaceutical samples.

\section{Stability studies}

\section{Stress testing}

Stress testing showed the formation of two principal degradation products identified as enalaprilat and diketopiperazine by comparing the chromatograms of stressed samples with chromatograms of standard solution of these compounds.

\section{Hydrolysis}

In all the studied stress conditions, the degradation of enalapril was higher under hydrolytic conditions, especially under alkaline stress; therefore degradation kinetics was obtained: After $30 \mathrm{~min}$ of hydrolysis in $0.1 \mathrm{~N}$ sodium hydroxide, the percentage of enalapril remaining was $7.5 \%$. After $24 \mathrm{~h}$ of hydrolysis in water and $0.1 \mathrm{~N}$ hydrochloric acid, the percentage of enalapril remaining was 95.2 and $80.4 \%$ respectively. In the three studied conditions the degradation followed first-order kinetics. The degradation rate constant and the time at which concentration fell to $90 \%$ of the original concentration $\left(t_{90}\right)$ are shown in Table 3.

Table 3. Degradation kinetics of enalapril under hydrolytic conditions

\begin{tabular}{cccc}
\hline $\begin{array}{c}\text { Stress } \\
\text { condition }\end{array}$ & $\begin{array}{c}\text { Temperature } \\
\left({ }^{\circ} \mathrm{C}\right)\end{array}$ & $K^{\mathrm{a})}$ & $\mathrm{t}_{90}{ }^{\mathrm{b})}$ \\
\hline $0.1 \mathrm{~N} \mathrm{NaOH}$ & 60 & $0.09141 / \mathrm{min}$ & $1.15 \mathrm{~min}$ \\
Water & 80 & $0.00181 / \mathrm{h}$ & $57.20 \mathrm{~h}$ \\
$0.1 \mathrm{~N} \mathrm{HCl}$ & 80 & $0.00901 / \mathrm{h}$ & $11.73 \mathrm{~h}$ \\
\hline
\end{tabular}

a) Degradation rate constant. b) Time at which concentration fell to $90 \%$ of the original concentration

Under alkaline stress, enalapril degraded to enalaprilat, under neutral condition, enalapril degraded to enalaprilat and especially to diketopiperazine and under acidic stress enalapril degraded to enalaprilat, diketopiperazine and a degradation product with that appeared between enalapril and salycilic acid (the major degradation product was DKP).

\section{Oxidation}

Enalapril was found to be stable under oxidative stress.

\section{Temperature}

No decomposition was seen on exposure of solid drug powder to dry heat at $70^{\circ} \mathrm{C}$ or $40 \pm 2{ }^{\circ} \mathrm{C} / 75 \pm 5 \% \mathrm{RH}$ for 27 days.

\section{Photostability}

The exposure of an aqueous solution of enalapril to UV and VIS radiation for 7 days resulted in a slight degradation to enalaprilat. In solid state, no degradation was observed.

\section{Accelerated stability testing}

The results obtained in the accelerated testing showed that most enalapril maleate tablets $10 \mathrm{mg}$ are highly susceptible to de- 
Table 4. Accelerated stability testing of enalapril maleate tablets $10 \mathrm{mg}$

\begin{tabular}{|c|c|c|c|c|c|c|c|c|}
\hline \multirow[t]{3}{*}{ Product } & \multicolumn{8}{|c|}{ Enalapril } \\
\hline & \multicolumn{2}{|c|}{0 days } & \multicolumn{2}{|c|}{30 days } & \multicolumn{2}{|c|}{90 days ${ }^{\text {a) }}$} & \multicolumn{2}{|c|}{180 days $^{\text {a) }}$} \\
\hline & $(\mathrm{mg})^{\mathrm{a})}$ & $(\%)$ & $(\mathrm{mg})^{\mathrm{a})}$ & $(\%)$ & $(\mathrm{mg})^{\mathrm{a})}$ & $(\%)$ & $(\mathrm{mg})^{\mathrm{a})}$ & $(\%)$ \\
\hline S & $9.97 \pm 0.05$ & 99.7 & $9.82 \pm 0.08$ & 98.2 & $9.80 \pm 0.01$ & 98.0 & $9.79 \pm 0.08$ & 97.9 \\
\hline RA & $9.77 \pm 0.12$ & 97.7 & $9.52 \pm 0.21$ & 95.2 & $9.13 \pm 0.07$ & 91.3 & $9.09 \pm 0.05$ & 90.9 \\
\hline $\mathrm{RB}$ & $9.23 \pm 0.13$ & 92.3 & $8.69 \pm 0.13$ & 86.9 & $7.99 \pm 0.08$ & 79.9 & $7.77 \pm 0.19$ & 77.7 \\
\hline $\mathrm{RC}$ & $9.30 \pm 0.09$ & 93.0 & $7.28 \pm 0.14$ & 72.8 & $5.88 \pm 0.09$ & 58.9 & $4.87 \pm 0.20$ & 48.7 \\
\hline GA & $9.22 \pm 0.15$ & 92.2 & $9.12 \pm 0.09$ & 91.2 & $9.07 \pm 0.02$ & 90.7 & $9.03 \pm 0.19$ & 90.3 \\
\hline GB & $8.89 \pm 0.12$ & 88.9 & $7.28 \pm 0.19$ & 72.8 & $5.77 \pm 0.13$ & 57.7 & $4.79 \pm 0.14$ & 47.9 \\
\hline GC & $9.13 \pm 0.08$ & 91.3 & $8.09 \pm 0.16$ & 80.9 & $5.01 \pm 0.14$ & 50.1 & $3.19 \pm 0.08$ & 31.9 \\
\hline
\end{tabular}

$\mathrm{S}=$ reference product. $\mathrm{R}=$ registered trade products. $\mathrm{G}=$ generic products. Mean $\pm \mathrm{SD}(\mathrm{n}=4)$.
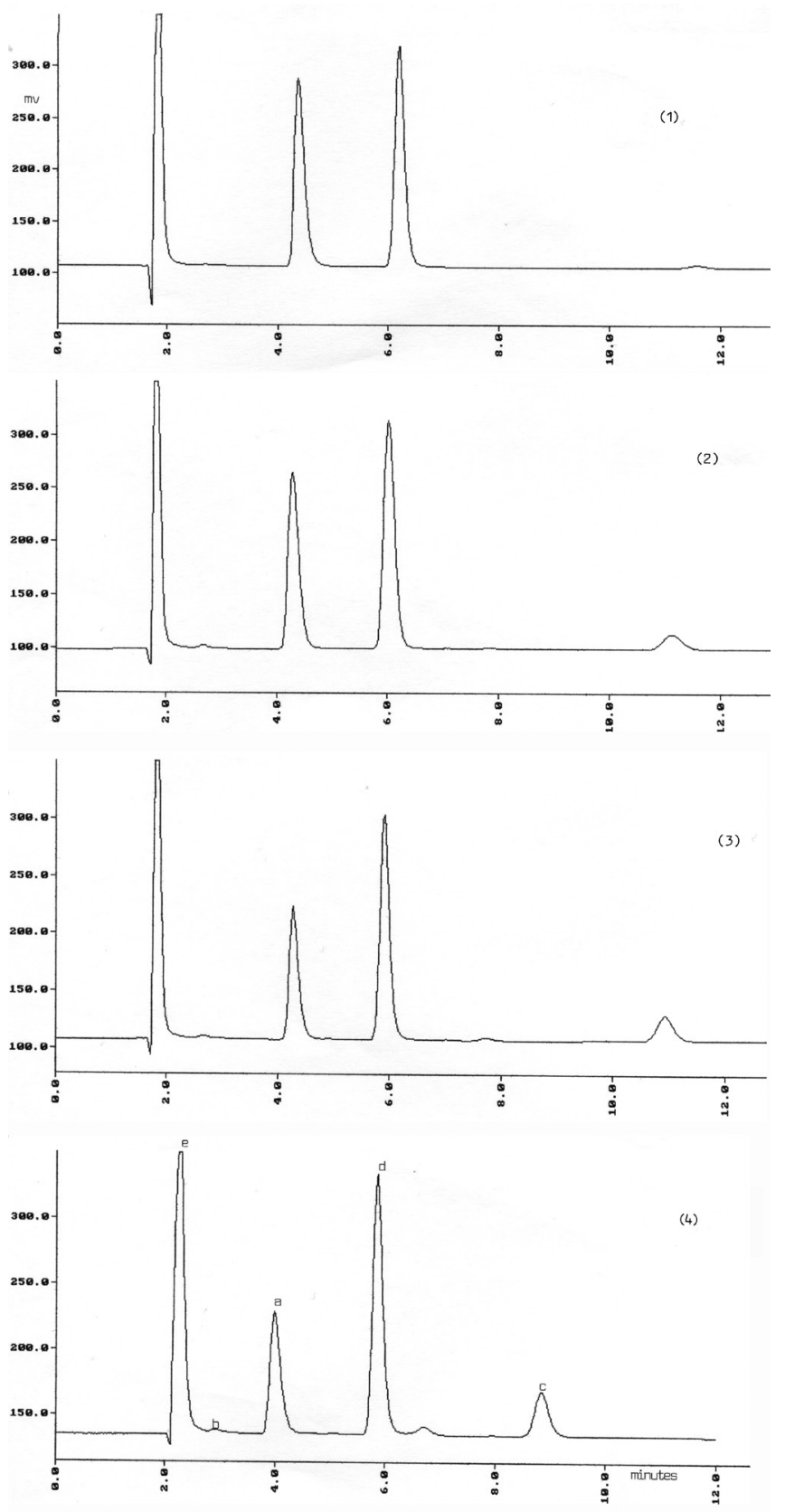

Figure 3. Representative chromatograms of enalapril maleate tablets $10 \mathrm{mg}$, product $G B$ stored under $40{ }^{\circ} \mathrm{C}$ and $75 \%$ RH at O (1), 30 (2), 90 (3) and 180 (4) days: enalapril (a), enalaprilat, (b) diketopiperazine (c), salicylic acid (d) and maleic acid (e). $1 \mathrm{mV}: 0.001 \mathrm{AU}$ gradation. According to the United States Pharmacopeia, ${ }^{2}$ enalapril maleate tablets must contain between $90-110 \%$ of the labelled amount, which corresponds to 9-11 mg. As show in Table 4, only reference product $(\mathrm{S})$, registered trade product RA and generic product GA (both from the same manufacturer) are within these limits throughout the study. Even product GB is outside of specifications at the beginning of the study (day 0). These results are in accordance with previous work, ${ }^{10}$ but the study was in tablets from the Brazilian market.

Under accelerated conditions, enalapril tablets degraded gradually to enalaprilat and especially to diketopiperazine as a function of the time of exposure to higher temperature and humidity. Figure 3 shows chromatograms of product GB showing the gradual increase of enalapril degradation during the study.

\section{CONCLUSIONS}

A simple stability-indicating LC method to determine the chemical stability of enalapril maleate drug substance and tablets has been developed and validated.

The results obtained from the stress testing show that the degradation of enalapril maleate drug substance in solution is higher under hydrolytic conditions especially under alkaline stress, whereas in solid state (powder) is highly stable.

The results obtained in the accelerated testing show that most enalapril maleate tablets $10 \mathrm{mg}$ are highly susceptible to degradation under moderate temperature and humidity $\left(40{ }^{\circ} \mathrm{C}\right.$ and $\left.75 \% \mathrm{RH}\right)$. Therefore, care should be taken in the manufacturing process and during storage of this product in order to avoid degradation, because amounts lower than $90 \%$, the product does not accomplishes with the pharmacopeial requirements, and thus, it could result in diminution of the therapeutic activity and safety.

\section{ACKNOWLEDGEMENT}

This work was supported by research project DIUC 208.074.0391.0, Research Department, University of Concepción.

\section{REFERENCES}

1. Lund, W.; The Pharmaceutical Codex, $12^{\text {th }}$ ed., the Pharmaceutical Press: London, 1994.

2. Farmacopea de los Estados Unidos de América, $30^{\text {th }}$ ed., United States Pharmacopeial Convection, Inc: Rockville, 2007.

3. Yoshioka, S.; Stella, V.; Stability of Drugs and Dosage Forms, Kluwer Academic Plenum Publishers: New York, 2000.

4. Carstensen, J.; Rhodes, C.; Drug Stability, Principles and Practices, $3^{\text {rd }}$ ed., Taylor \& Francis: New York, 2000. 
5. Mc Evoy, G. K.; AHFS Drug Information, American Society of HealthSystem Pharmacists: Bethesda, 2006.

6. Bhardwaj, S.; Singh, S.; J. Pharm. Biomed. Anal. 2008, 46, 113.

7. Stanisz, B.; J. Pharm. Biomed. Anal. 2003, 31, 375.

8. Al-Omari, M.; Abdelah, M.; Badwan, A.; Jaber, A.; J. Pharm. Biomed. Anal. 2001, 25, 893.

9. Stanisz, B.; Acta Pol. Pharm. 2004, 61, 415.

10. Lima, D.; Dos Santos, L.; Lima, E.; J. Pharm. Biomed. Anal. 2008, 47, 934.

11. Roskar, R.; Simoncic, Z.; Gartner, A.; Kmetec, V.; J. Pharm. Biomed. Anal. 2009, 49, 295.

12. Bhushan, R.; Gupta, D.; Singh, S.; Biomed Chromatogr. 2006, 20, 217.

13. Bonazzi, D.; Gotti, R.; Andrisano, V.; Cavrini, V.; J. Pharm. Biomed. Anal. 1997, 16, 431.
14. Toporisic, R.; Mlakar, A.; Hvala, J.; Prislan, I.; Zupancic-Kralj, L.; J. Pharm. Biomed. Anal. 2010, 52, 294.

15. Gu, Q.; Chen, X.; Zhong, D.; Wang, Y.; J. Chromatogr, B: Anal. Technol. Biomed. Life Sci. 2004, 813, 337.

16. Lu, S.; Jiang, K.; Qin, F.; Lu, X.; Li, F.; J. Pharm. Biomed. Anal. 2009, 49, 163.

17. ICH Q1 A (R2), Stability Testing of New Drug Substances and Products, International Conference on Harmonization, 2003.

18. ICH Q2B, Validation of Analytical Procedures: Methodology, International Conference on Harmonization, 1996.

19. Baertschi, S. In Pharmaceutical Stress Testing, Predicting Drug Degradation; Baertschi, S.; Lilly, E., eds.; Taylor \& Francis: Boca Raton, 2005, chap. 4. 